

\title{
The use of polymeric sulfides as catalysts for the para-regioselective chlorination of phenol and 2-chlorophenol
}

\author{
Keith Smith ${ }^{\text {a }}$, Amany S. Hegazy ${ }^{a, b}$ and Gamal A. El-Hiti ${ }^{(D)}$ \\ ${ }^{a}$ School of Chemistry, Cardiff University, Cardiff, UK; ${ }^{b}$ Department of Chemistry, University of Wales Swansea, \\ Swansea, UK; ' ${ }^{C}$ Cornea Research Chair, Department of Optometry, College of Applied Medical Sciences, King Saud \\ University, Riyadh, Saudi Arabia
}

\begin{abstract}
Various poly(alkylene sulfide)s have been synthesized and used as catalysts to enhance the para-regioselectivity in chlorination of phenol and 2-chlorophenol using freshly distilled sulfuryl chlo-ride in the presence of $\mathrm{AlCl}_{3}$ as an activator. Poly(alkylene sul-fide)s having alternating spacers, one having three methylene groups and the second having three, six or nine methylene groups were the most para-regioselective catalysts in chlorination of both phenol and 2-chlorophenol. For example, chlorination of phenol and 2chlorophenol in the presence of optimal examples of such poly(alkylene sulfide)s gave 4-chlorophenol and 2,4-dichlorophenol as the major products in 94.8 and $95.4 \%$ yields, respectively, compared with 75.4 and $55.0 \%$ yields in the absence of catalysts. In addi-tion, double chlorination of phenol in the presence of poly(alkylene sulfide)s gave 2,4-dichlrophenol in up to $97.1 \%$ yield compared with only $58.6 \%$ in the absence of catalysts.
\end{abstract}

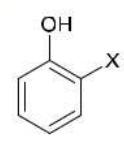

$\mathrm{X}=\mathrm{H}, \mathrm{Cl}$

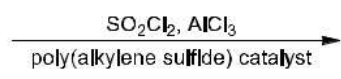
poly(alkylene sulflde) catalyst<smiles>Oc1ccc(Cl)cc1Cl</smiles>

\section{KEYWORDS}

Para-regioselective chlorination; catalysts; aluminum chloride; 2,4-dichlorophenol; phenol; poly(alkylene sulfide)s

\section{Introduction}

Chlorophenols are used in the production of many industrial products such as herbicides, pharmaceuticals and dyes [1]. For example, 2,4-dichlorophenoxyacetic is used in weed control for many crops such as maize and rice [2,3]. It is still widely used mainly due to its low production cost and can be produced from the reaction of molar equivalents of chloroacetic acid and 2,4-dichlorophenol (2,4-DCP) in the presence of an excess 
of sodium hydroxide [4]. Therefore, there is continuing interest in the development of low-cost processes for the selective production of chlorophenols.

Recently, several processes have been developed for the selective halogenation of aromatic compounds [5-10]. For example, chlorination systems involving the use of [bis(trifluoroacetoxy)iodo]benzene and aluminum chloride $(\mathrm{AlCl} 3)$ in acetonitrile [5], 1,3-dichloro-5,5-dimethylhydantoin in the presence of ammonium chloride in toluene [6], hydrogen chloride, manganese(II) sulfate and hydrogen peroxide in water [7], and $\mathrm{N}$-chlorosuccinimide and Nagasawa's bisthiourea catalyst in chlorinated solvent [8] have been reported. However, such systems are often selective towards the orthoisomers and involve use of solvent, which are not applicable for the commercial production of bulk chlorophenols.

We have reported a number of efficient processes that employ solid catalysts to enhance the regioselective production of para- or linear isomers in electrophilic substitution of aromatic compounds [11-25]. Sheldon's group has used a similar approach for chlo-rination of phenol (P) using $\mathrm{SO}_{2} \mathrm{Cl}_{2}$ in the presence of $\mathrm{L}$ type zeolite in isooctane to give 2-chlorophenol (2-CP) and 4-chlorophenol (4-CP) in 10.7 and $85.3 \%$ yields, respectively [26]. Under similar reaction conditions, the use of Al-pillared montmo-rillonite clay as a catalyst gave $2-\mathrm{CP}$ and $4-\mathrm{CP}$ in 13.4 and $75.7 \%$ yields, respectively [26]. Others have adopted different approaches to chlorination of phenols with various chlorinating agents [27,28]. However, one of the most promising approaches for commer-cially relevant selective para-chlorination of phenols involves the use of sulfur-containing catalysts.

Selective chlorination of phenols using $\mathrm{SO}_{2} \mathrm{Cl}_{2}$ in the presence of sulfur-containing cata-lysts and Lewis acids was f irst reported by Watson [29,30]. For example, monochlorination of $\mathrm{P}$ using $\mathrm{SO}_{2} \mathrm{Cl}_{2}$ in the presence of diphenyl sulf ide $\left(\mathrm{Ph}_{2} \mathrm{~S}\right)$ and $\mathrm{AlCl}_{3}$ at $25^{\circ} \mathrm{C}$ gave $2-\mathrm{CP}$ and $4-\mathrm{CP}$ in 8.5 and $89.5 \%$ yields, respectively [29,30]. Similarly, chlorination of 2-CP in the presence of ferric chloride $(\mathrm{FeCl} 3)$ at $35^{\circ} \mathrm{C}$ gave $2,4-\mathrm{DCP}$ and 2,6-dichlorophenol (2,6-DCP) in 94.0 and $4.2 \%$ yields, respectively [29,30]. Double chlorination of $\mathrm{P}$ using $\mathrm{SO}_{2} \mathrm{Cl}_{2}$ in the presence of $\mathrm{Ph}_{2} \mathrm{~S}$ and $\mathrm{FeCl}_{3}$ at $25^{\circ} \mathrm{C}$ gave 2,4DCP (97.3\%), 2,6-DCP (0.4\%) and 2,4,6-trichlorophenol (2.0\%) [29,30].

Since then, various other sulfur compounds have been investigated as catalysts in the chlorination of $\mathrm{P}$ and $2-\mathrm{CP}$. For example, chlorination of $\mathrm{P}$ using $\mathrm{SO}_{2} \mathrm{Cl}_{2}$ and di- $n$-butyl sulfide in the absence of a Lewis acid at $25^{\circ} \mathrm{C}$ gave 2-CP, 4-CP, and 2,4-DCP in 8.7, 84.8, and $1.0 \%$ yields, respectively, along with unreacted starting material $(5.4 \%)$ [31,32]. Chlorination of $\mathrm{P}$ using $\mathrm{SO}_{2} \mathrm{Cl}_{2}$ in the presence of the cyclic disulfide 1,2-dithiocane and $\mathrm{AlCl}_{3}$ at $25^{\circ} \mathrm{C}$ gave $2-\mathrm{CP}(7.4 \%), 4-\mathrm{CP}(91.2 \%)$, and 2,4-DCP $(1.1 \%)$ [33], while use of the polymeric equivalent, poly(hexamethylenedisulfide), under similar conditions gave 2-CP, 4-CP and 2,4-DCP in 8.8, 89.0, and 2.2\% yields, respectively [33]. The use of tetrahydrothiopyran as catalyst in chlorination of $\mathrm{P}$ using $\mathrm{SO}_{2} \mathrm{Cl}_{2}$ in the presence of $\mathrm{AlCl}_{3}$ at $25^{\circ} \mathrm{C}$ gave $2-\mathrm{CP}$ and 4-CP in 5.0 and $89.0 \%$ yields, respectively [34], while chlorination of $\mathrm{P}$ using $\mathrm{SO}_{2} \mathrm{Cl}_{2}$ in the presence of 5,18-dithiadocosane and $\mathrm{AlCl} 3$ at $35^{\circ} \mathrm{C}$ gave 2-CP and 4-CP in 6.6 and $76.4 \%$ yields, respectively, along with unreacted starting material (11.4\%) [35,36]. Methylthio alcohols, methoxy(methylthio)alkanes, and bis(methythio)alkanes have also been investigated as catalysts in chlorination of $\mathrm{P}$ using $\mathrm{SO}_{2} \mathrm{Cl}_{2}$ in the presence of $\mathrm{AlCl}_{3}$ at $25^{\circ} \mathrm{C}$ and led to the production 2-CP $(8.2-12.7 \%)$ and 4-CP $(83.1-88.8 \%)$ along with 2,4-DCP (1.6-2.3\%) [37]. 
We have previously had occasion to synthesize a series of poly(alkylene sulfide)s [38], which we have used to make stable borane complexes [39,40], and in the patent litera-ture we have also reported a more complex poly(alkylene sulfide) with a repeating unit $\left[\left(\mathrm{CH}_{2}\right)_{8} \mathrm{~S}\left(\mathrm{CH}_{2}\right)_{6} \mathrm{~S}\right]$ [36]. Such solid sulfur-containing materials could combine some of the advantages of solid reagents (such as ease of removal by filtration, lack of odor) with some of the benefits of sulfur compounds (as regioselective catalysts). Therefore, we now report the preparation of further examples of more complex poly(alkylene sulfide)s hav-ing alternating alkylenethio groups of different chain lengths and their use, along with the use of symmetrical poly(alkylene sulfide)s, in the regioselective chlorination of phenol and 2-chlorophenol using $\mathrm{SO}_{2} \mathrm{Cl}_{2}$ and $\mathrm{AlCl}_{3}$.

\section{Results and discussion}

A range of poly(alkylene sulfide)s was synthesized using two different synthetic approaches. The first one involved lithiation of $1, \omega$-alkanedithiols (one mole equivalent) using $n$ butyllithium ( $n-\mathrm{BuLi}$; two mole equivalents) in tetrahydrofuran (THF) at low temperature followed by reaction with $1, \omega$-dibromoalkanes $(0.9$ mole equivalent) and 1-bromobutane ( 0.2 mole equivalent) at room temperature (Scheme 1). Such a procedure allowed the production in 75-96\% yields of poly(alkylene sulfide)s 1-19 that have alter-nating spacer units of different chain lengths (number of methylene groups) (Table 1). The second procedure involved reaction of $1, \omega$-dibromoalkanes (one mole equivalent) and sodium sulfide nonahydrate $\left(\mathrm{Na}_{2} \mathrm{~S} .9 \mathrm{H}_{2} \mathrm{O} ; 1.4\right.$ mole equivalents) under reflux conditions for $4 \mathrm{~h}$ (Scheme 2), in accordance with the reported procedure [38]. This method was used to synthesize poly(alkylene sulfide)s 20-24 that had just one type of spacer unit in 83-97\% yields (Table 2). This method was successfully applied for the production of poly(alkylene sulfide)s that had 2-8 methylene units as spacers. The latter approach was also used on an equimolar mixture of two different dibromoalkanes, resulting in a poly(alkylene sulfide) $\mathbf{2 5}$ with two different spacer groups, but not uniformly distributed (Scheme 3). The gen-eral natures of the synthesized poly(alkylene sulfide)s 1-25 were confirmed by the use of ${ }^{1} \mathrm{H}$ NMR spectral data and where comparisons were possible were consistent with those previously reported [38].

Chlorination of $\mathrm{P}(100 \mathrm{mmol})$ using distilled $\mathrm{SO}_{2} \mathrm{Cl}_{2}(110 \mathrm{mmol})$ in the presence of poly(alkylene sulfide)s (100 mg) as catalysts and $\mathrm{AlCl}_{3}(100 \mathrm{mg})$ as a Lewis acid in the absence of solvent was attempted at $25^{\circ} \mathrm{C}$ (Scheme 4; route a). In addition, the reaction was carried out in the absence of poly(alkylene sulfide)s under the same conditions for comparison. The yields of the chlorinated products obtained (2-CP, 4-CP and 2,4-DCP) are reported in Table 3.

$$
\begin{aligned}
& \text { 1, } n \text {-BuLi, THF, }-78^{\circ} \mathrm{C} \\
& \mathrm{HS}\left(\mathrm{CH}_{2}\right)_{n} \mathrm{SH} \stackrel{2, \mathrm{Br}\left(\mathrm{CH}_{2}\right)_{\mathrm{m}} \mathrm{Br}, 25^{\circ} \mathrm{C}}{3, n-\mathrm{BuBr}, 25^{\circ} \mathrm{C}} \mathrm{BuS}\left(\mathrm{CH}_{2}\right)_{n} \mathrm{~S}\left[\left(\mathrm{CH}_{2}\right)_{\mathrm{m}} \mathrm{S}\left(\mathrm{CH}_{2}\right)_{n} \mathrm{~S}\right]_{y} \mathrm{Bu} \\
& \text { 4, } \mathrm{H}_{2} \mathrm{O} \\
& \text { 1-19 }(75-96 \%) \\
& n, m=2-12
\end{aligned}
$$

Scheme 1. Synthesis of poly(alkylene sulfide)s 1-19 using alkanedithiols. 
Table 1. Synthesis of poly(alkylene sulfide)s 1-19 according to Scheme 1.

\begin{tabular}{llrcc}
\hline Polymer & $\mathrm{n}$ & $\mathrm{m}$ & Melting point $\left({ }^{\circ} \mathrm{C}\right)$ & Yield $(\%)$ \\
\hline $\mathbf{1}$ & 2 & 2 & $165-168$ & 75 \\
$\mathbf{2}$ & 3 & 3 & $64-67$ & 82 \\
$\mathbf{3}$ & 3 & 4 & $60-63$ & 94 \\
$\mathbf{4}$ & 3 & 6 & $63-65$ & 83 \\
$\mathbf{5}$ & 3 & 9 & $71-73$ & 84 \\
$\mathbf{6}$ & 3 & $83-85$ & 93 \\
$\mathbf{7}$ & 3 & 4 & $68-70$ & 90 \\
$\mathbf{8}$ & 4 & 6 & $69-72$ & 80 \\
$\mathbf{9}$ & 4 & 8 & $75-78$ & 95 \\
$\mathbf{1 0}$ & 4 & 10 & $80-84$ & 92 \\
$\mathbf{1 1}$ & 4 & 12 & $86-90$ & 96 \\
$\mathbf{1 2}$ & 4 & 5 & $69-70$ & 96 \\
$\mathbf{1 3}$ & 4 & 6 & $74-77$ & 94 \\
$\mathbf{1 4}$ & 5 & 10 & $74-77$ & 93 \\
$\mathbf{1 5}$ & 6 & 12 & $78-81$ & 89 \\
$\mathbf{1 6}$ & 6 & 8 & $78-83$ & 98 \\
$\mathbf{1 7}$ & 6 & 10 & $78-84$ & 90 \\
$\mathbf{1 8}$ & 6 & 12 & $85-88$ & 91 \\
$\mathbf{1 9}$ & 6 & & & \\
\hline
\end{tabular}

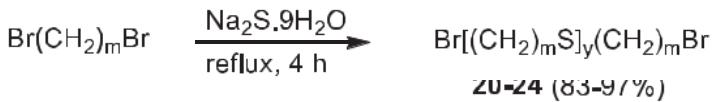

$$
\begin{aligned}
& m=2-8
\end{aligned}
$$

Scheme 2. Synthesis of poly(alkylene sulfide)s 20-24 using sodium sulfide.

Table 2. Synthesis of poly(alkylene sulfide)s 20-24 according to Scheme 2.

\begin{tabular}{llcc}
\hline Polymer & $\mathrm{m}$ & Melting point $\left({ }^{\circ} \mathrm{C}\right)$ & Yield $(\%)$ \\
\hline $\mathbf{2 0}$ & 2 & $185-186$ & 90 \\
$\mathbf{2 1}$ & 3 & $55-57$ & 90 \\
$\mathbf{2 2}$ & 4 & $66-69$ & 83 \\
$\mathbf{2 3}$ & 6 & $70-77$ & 97 \\
$\mathbf{2 4}$ & 8 & $58-64$ & 94 \\
\hline
\end{tabular}

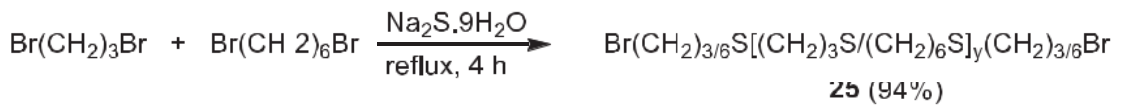

Scheme 3. Synthesis of mixed poly(alkylene sulfide) 25 using sodium sulfide.

The yield of 4-CP was only $75.4 \%$ when the reaction was carried out in the absence of any catalyst (Table 3 ). The yield of 4-CP improved in all cases when a poly(alkylene sulfide) was used as a catalyst. Catalysts containing at least one shorter spacer unit (at most three methylene groups) invariably provided higher yields of 4-CP (87.2-91.4\%) than those having only longer spacers containing at least five methylene groups (78.2-85.0\%). Catalysts in which the shortest spacer group was four methylene units provided intermediate yields (82.4-90.3\%), depending on the length of the longer spacer group (catalysts with longer second spacers giving lower yields of 4-CP). The same trends can be seen in the 4-CP/2-CP ratios ( $p / o$ ratios). Poly(alkylene sulfide) 5 , which contains alternating spacers of three 
Table 3. Chlorination of phenol according to Scheme 4 (route a). ${ }^{a}$

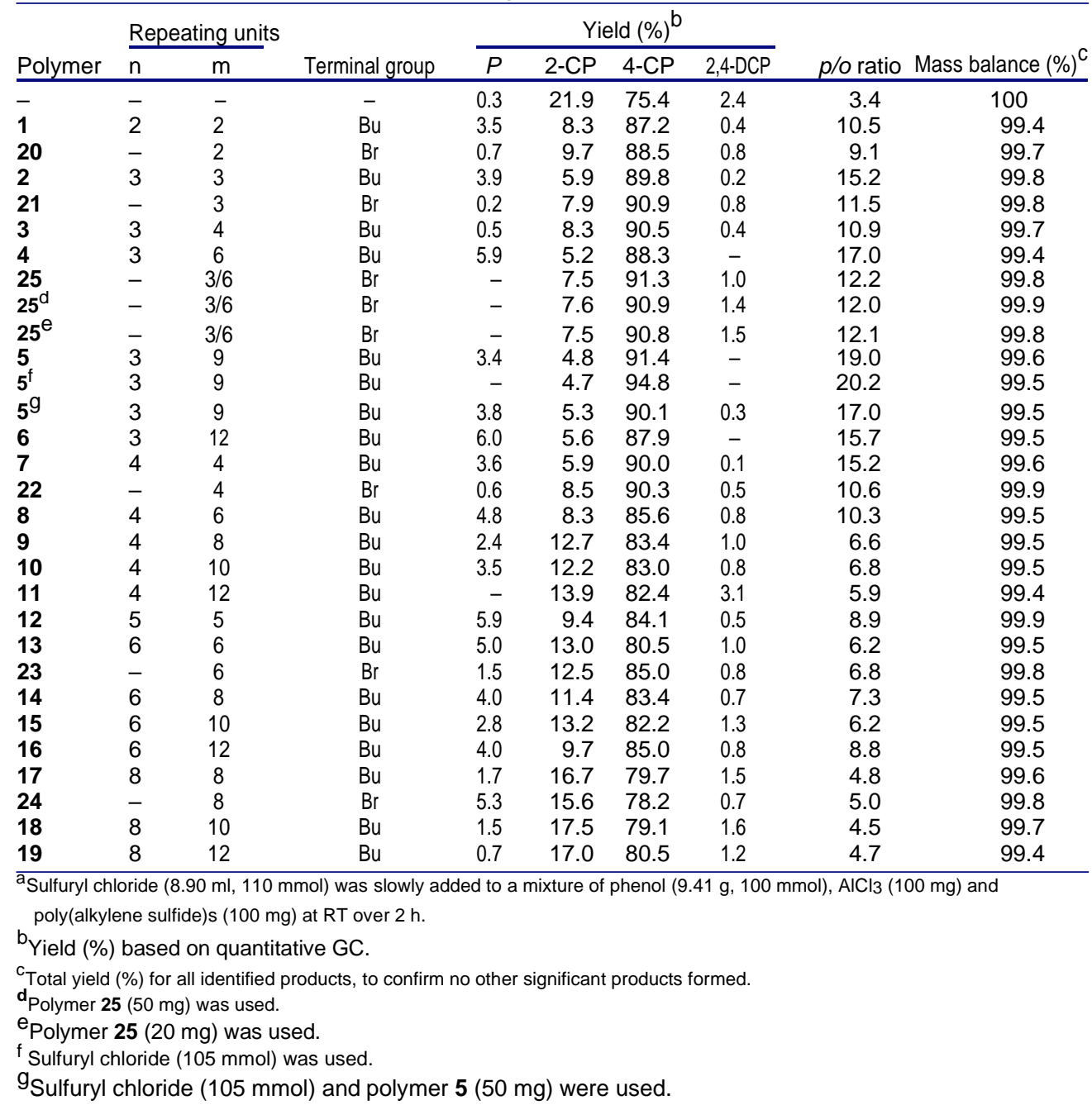

and nine methylene groups (i.e. $\mathrm{n}=3, \mathrm{~m}=9$ ), was the most para-regioselective catalyst in chlorination of $\mathrm{P}$, producing $4-\mathrm{CP}$ in $91.4 \%$ yield under the standard conditions, which increased to $94.8 \%$ when the mixture was stirred at $55^{\circ} \mathrm{C}$ for $1 \mathrm{~h}$ before work-up. This was the highest 4-CP yield achieved from any of the reactions. Reducing the quantity of 5 to $50 \mathrm{mg}$ and $\mathrm{SO}_{2} \mathrm{Cl}_{2}$ to $105 \mathrm{mmol}$ led to the production of 4-CP in $90.1 \%$ yield along with a significant quantity of unreacted P (3.8\%). Poly(alkylene sulfide) 25 $(\mathrm{m}=3 / 6)$ was also highly selective, leading to the production of $4-\mathrm{CP}$ in $91.3 \%$ under the standard condi-tions and giving very similar results with lower quantities $(50 \mathrm{mg}$ or $20 \mathrm{mg}$ ) of 25 under otherwise similar reaction conditions.

Polymers with similar spacer groups but prepared by the different methods, one major difference therefore being the nature of the terminal group ( $\mathrm{Bu}$ or $\mathrm{Br}$ ), gave broadly similar results when direct comparisons were possible, suggesting that the length of the spacer groups has more effect than the nature of the terminal groups or the method of preparation. Nevertheless, in the cases with at least one short spacer group (at least one group being no 


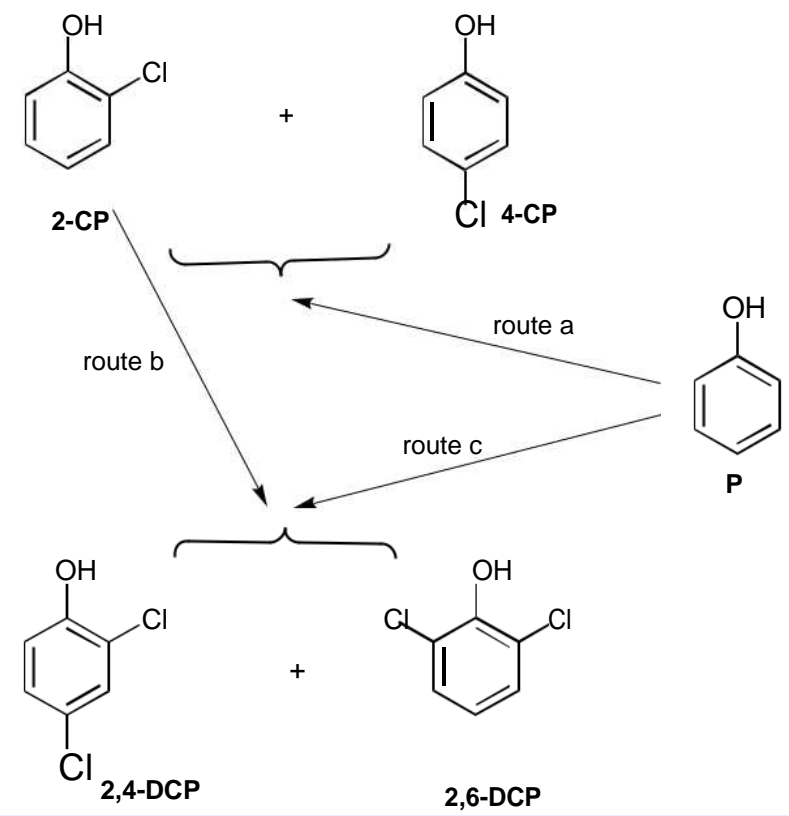

Reagents used in different routes (all at RT for $2 \mathrm{~h}$ unless otherwise stated)

route a: $\mathrm{P}(100 \mathrm{mmol}), \mathrm{SO}_{2} \mathrm{Cl}_{2}(110 \mathrm{mmol})$, polymer 1-25 $(0.1 \mathrm{~g}), \mathrm{AlCl}_{3}(0.1 \mathrm{~g})$ route b: $2-\mathrm{CP}(100 \mathrm{mmol}), \mathrm{SO}_{2} \mathrm{Cl}_{2}(110 \mathrm{mmol})$, polymer $1-25(0.1 \mathrm{~g}), \mathrm{AlCl}_{3}(0.1 \mathrm{~g})$ route c: $\mathrm{P}(100 \mathrm{mmol}), \mathrm{SO}_{2} \mathrm{Cl}_{2}(210 \mathrm{mmol})$, polymer $1-25(0.1 \mathrm{~g}), \mathrm{AlCl}_{3}(01 \mathrm{~g})$

Scheme 4. Chlorination of phenol $(P)$ or 2-chlorophenol (2-CP) using sulfuryl chloride in the presence of poly(alkylene sulfide)s 1-25 and $\mathrm{AlCl} 3$.

longer than trimethylene, or both being tetramethylene, which were the polymers giving higher $p / o$ ratios), the $p / o$ ratio was somewhat greater with the polymer made using the alkanedithiol route shown in Scheme 1 (i.e. $1>20 ; 2>21 ; 4>25 ; 7>22$ ). By contrast, for polymers with longer spacers, which generally did not give high $p / o$ ratios, the polymer made using Scheme 2 gave a somewhat greater $p / o$ ratio than the corresponding example made by the alkanedithiol route (i.e. $23>13 ; 24>17$ ).

The fact that the presence of any of the polymers resulted in a higher $p / o$ ratio than in their absence is consistent with the previously expressed view that the sulfur-containing catalyst forms a bulky electrophilic complex with the $\mathrm{AlCl}_{3}$ and $\mathrm{SO}_{2} \mathrm{Cl}_{2}$ that attacks the $\mathrm{P}$ at the least hindered 4-position to produce 4-CP as the major product $[29,30]$. However, this simplistic idea does not explain the subtleties displayed by the polymers with different spacer groups.

In view of the commercial importance of 2,4-dichlorophenol, and in recognition that further chlorination of 4-CP would give virtually exclusively 2,4-DCP, it was of interest to investigate the further chlorination of 2-CP (Scheme 4, route b), which could give both 2,4-DCP and 2,6-DCP, under similar conditions to those used for the chlorination of P. The yields and $p / o$ ratio for the chlorinated products $(2,4-\mathrm{DCP}$ and $2,6-\mathrm{DCP})$ are reported in Table 4.

Under the standard conditions, in the absence of any poly(alkylene sulfide), the yields of 2,4-DCP and 2,6-DCP were 55.0 and $12.5 \%$, respectively, along with a high proportion 
Table 4. Chlorination of 2-chlorophenol according to Scheme 4 (route b). ${ }^{a}$

\begin{tabular}{|c|c|c|c|c|c|c|c|c|}
\hline \multicolumn{3}{|c|}{ Repeatingunits } & \multicolumn{4}{|c|}{ Yield $(\%)^{b}$} & \multirow[b]{2}{*}{$p / o$ ratio } & \multirow[b]{2}{*}{ Mass balance $(\%)^{C}$} \\
\hline Polymer & $\mathrm{n}$ & $\mathrm{m}$ & Terminal group & $2-\overline{C P}$ & 2,4-DCP & 2,6-DCP & & \\
\hline- & - & - & - & 32.4 & 55.0 & 12.5 & 4.4 & 99.9 \\
\hline 2 & 3 & 3 & $\mathrm{Bu}$ & 11.5 & 84.0 & 4.2 & 20.0 & 99.7 \\
\hline $2^{d}$ & 3 & 3 & $\mathrm{Bu}$ & 0.4 & 95.4 & 3.7 & 25.8 & 99.5 \\
\hline 5 & 3 & 9 & $\mathrm{Bu}$ & 9.6 & 84.1 & 5.7 & 14.8 & 99.4 \\
\hline 7 & 4 & 4 & $\mathrm{Bu}$ & 5.9 & 84.6 & 8.5 & 10.0 & 99.0 \\
\hline $7^{d}$ & 4 & 4 & $\mathrm{Bu}$ & 2.0 & 90.7 & 6.8 & 13.3 & 99.5 \\
\hline 22 & - & 4 & $\mathrm{Br}$ & 13.0 & 80.7 & 5.9 & 13.7 & 99.6 \\
\hline 8 & 4 & 6 & $\mathrm{Bu}$ & 9.9 & 84.5 & 5.3 & 15.9 & 99.7 \\
\hline $8 d$ & 4 & 6 & $\mathrm{Bu}$ & 1.4 & 92.1 & 5.7 & 16.2 & 99.2 \\
\hline 9 & 4 & 8 & $\mathrm{Bu}$ & 3.7 & 89.8 & 6.0 & 15.0 & 99.5 \\
\hline 10 & 4 & 10 & $\mathrm{Bu}$ & 8.0 & 85.7 & 6.1 & 14.0 & 99.8 \\
\hline 11 & 4 & 12 & $\mathrm{Bu}$ & 19.6 & 73.7 & 6.4 & 11.5 & 99.7 \\
\hline 13 & 6 & 6 & $\mathrm{Bu}$ & 13.9 & 76.8 & 8.9 & 8.6 & 99.6 \\
\hline 14 & 6 & 8 & $\mathrm{Bu}$ & 12.1 & 76.3 & 11.1 & 6.9 & 99.5 \\
\hline 15 & 6 & 10 & $\mathrm{Bu}$ & 17.2 & 72.6 & 9.9 & 7.3 & 99.7 \\
\hline 16 & 6 & 12 & $\mathrm{Bu}$ & 17.6 & 71.9 & 10.0 & 7.2 & 99.5 \\
\hline 17 & 8 & 8 & $\mathrm{Bu}$ & 14.3 & 78.8 & 6.6 & 11.9 & 99.7 \\
\hline 18 & 8 & 10 & $\mathrm{Bu}$ & 19.0 & 70.8 & 9.7 & 7.3 & 99.5 \\
\hline 19 & 8 & 12 & $\mathrm{Bu}$ & 16.4 & 70.5 & 12.1 & 5.8 & 99.0 \\
\hline \multicolumn{9}{|c|}{$\begin{array}{l}\text { a Sulfuryl chloride ( } 8.90 \mathrm{ml}, 110 \mathrm{mmol}) \text { was slowly added to a mixture of 2-chlorophenol (12.86 g, } 100 \mathrm{mmol}), \mathrm{AlCl}_{3}(100 \mathrm{mg}) \text { and } \\
\text { poly(alkylene sulfide) }(100 \mathrm{mg}) \text { at RT over } 2 \mathrm{~h} \text {. }\end{array}$} \\
\hline \multicolumn{9}{|c|}{ byield (\%) based on quantitative GC. } \\
\hline${ }^{\mathrm{C}}$ Total yield & & & products, to co & 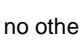 & 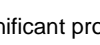 & ts forme & & \\
\hline
\end{tabular}

(32.4\%) of unreacted 2-CP (Table 4). In the presence of any one of the poly(alkylene sulfide)s, the yield of 2,4-DCP increased significantly (up to 89.9\%) while the yield of 2,6-DCP decreased, leading in all cases, therefore, to a higher $p / o$ ratio. However, there were significant differences in the level of selectivity observed with the different poly(alkylene sulfide)s. Generally, poly(alkylene sulfide)s with shorter spacers $(\mathrm{n}=3,4$ and $\mathrm{m}=3-8$ ) led to higher yields of 2,4-DCP and higher $p / o$ ratios than the ones with longer spacer units $(\mathrm{n}=$ $6,8$ and $\mathrm{m}=6-12)$. However, a significant quantity $(3.7-19.0 \%)$ of unreacted 2-CP still remained in the product mixtures and this could complicate the interpretation of the results. For example, with the only poly(alkylene sulfide) prepared by the sodium sulfide method (Scheme 2), polymer 22, $13 \%$ of 2-CP remained, resulting in a lower yield of 2,4-DCP $(80.7 \%)$ than for the corresponding polymer prepared according to Scheme 1 (i.e. 7, 84.6\%), despite giving a higher $p / o$ ratio (13.7 compared to 10.0). Therefore, three of the poly(alkylene sulfide)s that produced high yields of 2,4-DCP were used in reactions conducted under more forcing conditions (stirred at $55^{\circ} \mathrm{C}$ for $1 \mathrm{~h}$ before work-up). The yield of 2,4-DCP increased to over $90 \%$ in all three cases and poly(alkylene sulfide) $2(\mathrm{n}, \mathrm{m}=3$ ) provided a p/o ratio of 25.8 and the highest yield of 2,4-DCP (95.4\%) ever recorded on chlorination of 2-CP using $\mathrm{SO}_{2} \mathrm{Cl}_{2}$.

With the benefit of the information derived from monochlorination of phenol and chlorination of 2-CP, it was of interest to investigate the direct double chlorination of phenol. A significant quantity of starting material was recovered in chlorination of 2-CP under the general conditions, which negatively affected the yield of 2,4-DCP. Therefore, for the double chlorination of $\mathrm{P}$ (100 mmol) (Scheme 4, route c) a small excess of $\mathrm{SO}_{2} \mathrm{Cl} 2$ (210 mmol) was used, along with a poly(alkylene sulfide) and $\mathrm{AlCl} 3$, in an attempt to produce 2,4-DCP 
Table 5. Double chlorination of phenol according to Scheme 4 (route c). ${ }^{a}$

\begin{tabular}{|c|c|c|c|c|c|c|c|c|c|}
\hline \multirow[b]{2}{*}{ Polymer } & \multicolumn{3}{|c|}{ Repeating units } & \multicolumn{4}{|c|}{ Yield $(\%)^{b}$} & \multirow[b]{2}{*}{$p / o$ ratio } & \multirow[b]{2}{*}{ Mass balance $(\%)^{\mathrm{C}}$} \\
\hline & $n$ & $\mathrm{~m}$ & Terminal group & $2-\mathrm{CP}$ & 4-CP & 2,4-DCP & 2,6-DCP & & \\
\hline- & - & - & - & 9.0 & 29.2 & 58.6 & 3.0 & 19.5 & 99.8 \\
\hline 1 & 2 & 2 & $\mathrm{Bu}$ & 0.4 & 3.7 & 95.1 & 0.7 & 135.9 & 99.9 \\
\hline 20 & - & 2 & $\mathrm{Br}$ & 0.3 & 4.6 & 94.0 & 0.7 & 134.3 & 99.6 \\
\hline 2 & 3 & 3 & $\mathrm{Bu}$ & 1.6 & 37.8 & 59.7 & 0.4 & 149.2 & 99.5 \\
\hline 21 & - & 3 & $\mathrm{Br}$ & 0.8 & 23.0 & 75.7 & 0.4 & 189.3 & 99.9 \\
\hline 3 & 3 & 4 & $\mathrm{Bu}$ & 0.8 & 21.7 & 76.9 & 0.4 & 192.3 & 99.8 \\
\hline 4 & 3 & 6 & $\mathrm{Bu}$ & 2.0 & 34.4 & 62.9 & 0.6 & 104.8 & 99.9 \\
\hline 25 & - & $3 / 6$ & $\mathrm{Br}$ & 0.4 & 18.7 & 80.4 & 0.4 & 201.0 & 99.9 \\
\hline 5 & 3 & 9 & $\mathrm{Bu}$ & 1.1 & 28.3 & 69.9 & 0.2 & 349.5 & 99.5 \\
\hline $5 d$ & 3 & 9 & $\mathrm{Bu}$ & 0.4 & 9.6 & 89.2 & 0.3 & 279.3 & 99.5 \\
\hline $5^{\mathrm{e}}$ & 3 & 9 & $\mathrm{Bu}$ & - & 5.5 & 93.3 & 0.3 & 331.0 & 99.1 \\
\hline $5 f$ & 3 & 9 & $\mathrm{Bu}$ & - & 2.1 & 96.6 & 0.3 & 321.7 & 99.0 \\
\hline $5^{g}$ & 3 & 9 & $\mathrm{Bu}$ & 0.4 & 0.4 & 97.1 & 0.9 & 107.9 & 98.8 \\
\hline 6 & 3 & 12 & $\mathrm{Bu}$ & 1.8 & 28.5 & 68.9 & 0.7 & 98.4 & 99.9 \\
\hline 7 & 4 & 4 & $\mathrm{Bu}$ & 1.8 & 31.9 & 65.6 & 0.2 & 328.0 & 99.5 \\
\hline 22 & - & 4 & $\mathrm{Br}$ & 1.3 & 37.6 & 60.4 & 0.2 & 302.0 & 99.5 \\
\hline 8 & 4 & 6 & $\mathrm{Bu}$ & 4.5 & 27.4 & 66.7 & 1.1 & 60.6 & 99.7 \\
\hline 9 & 4 & 8 & $\mathrm{Bu}$ & 6.6 & 36.5 & 54.9 & 1.6 & 34.3 & 99.6 \\
\hline 10 & 4 & 10 & $\mathrm{Bu}$ & 3.6 & 24.4 & 70.1 & 1.5 & 46.7 & 99.6 \\
\hline 11 & 4 & 12 & $\mathrm{Bu}$ & 4.3 & 32.2 & 61.4 & 1.6 & 38.4 & 99.5 \\
\hline 13 & 6 & 6 & $\mathrm{Bu}$ & 5.6 & 25.8 & 66.0 & 2.1 & 31.4 & 99.5 \\
\hline 23 & - & 6 & $\mathrm{Br}$ & 2.5 & 18.3 & 77.1 & 2.0 & 38.6 & 99.9 \\
\hline 14 & 6 & 8 & $\mathrm{Bu}$ & 4.8 & 24.4 & 67.9 & 2.3 & 29.5 & 99.4 \\
\hline 15 & 6 & 10 & $\mathrm{Bu}$ & 4.9 & 29.4 & 63.3 & 1.8 & 35.2 & 99.4 \\
\hline 16 & 6 & 12 & $\mathrm{Bu}$ & 4.1 & 21.5 & 71.8 & 2.1 & 34.2 & 99.5 \\
\hline 17 & 8 & 8 & $\mathrm{Bu}$ & 8.7 & 39.4 & 49.4 & 2.0 & 24.7 & 99.5 \\
\hline 24 & - & 8 & $\mathrm{Br}$ & 2.3 & 9.9 & 84.3 & 3.2 & 26.3 & 99.7 \\
\hline 18 & 8 & 10 & $\mathrm{Bu}$ & 6.9 & 28.8 & 61.2 & 2.5 & 29.0 & 99.4 \\
\hline 19 & 8 & 12 & $\mathrm{Bu}$ & 4.5 & 18.1 & 74.1 & 2.7 & 27.4 & 99.4 \\
\hline
\end{tabular}

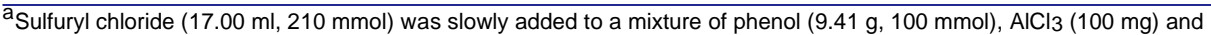
poly(alkylene sulfide) $(100 \mathrm{mg})$ at RT over $2 \mathrm{~h}$.

${ }^{b}$ Yield (\%) based on quantitative GC.

${ }^{\mathrm{c}}$ Total yield (\%) for all identified products, to confirm no other significant products formed. ${ }^{\mathrm{d}}$ The mixture was stirred at $55^{\circ} \mathrm{C}$ for $1 \mathrm{~h}$ before work-up

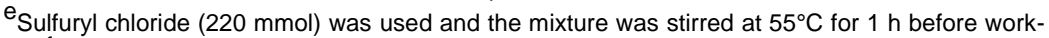
up. ${ }^{f}$ Sulfuryl chloride $(230 \mathrm{mmol})$ was used and the mixture was stirred at $55^{\circ} \mathrm{C}$ for $1 \mathrm{~h}$ before work-up. ${ }^{9}$ Sulfuryl chloride $(215 \mathrm{mmol})$ was used and the reaction was carried out at $55^{\circ} \mathrm{C}$.

directly in one step and in high yield without over-chlorination. The yields of 2,4-DCP and 2,6-DCP obtained are recorded in Table 5.

In the absence of poly(alkylene sulfide) and $\mathrm{AlCl}_{3}$, the yields of 2-CP, 4-CP, 2,4-DCP, and 2,6-DCP were 9.0, 29.2, 58.6, and 3.0\%, respectively, and the 2,4-/2,6-DCP ratio was less than 20 (Table 5). The yield of 2,4-DCP under the general conditions increased in all cases when poly(alkylene sulfide)s were used and the yield was highest for poly(alkylene sulfide)s containing at least one short spacer unit $(n=2$ or 3 and $m=2-9)$. For example, poly(alkylene sulfide)s 1 and $\mathbf{2 0}(\mathrm{n}, \mathrm{m}=2)$ provided the highest yields of 2,4-DCP (94.0 and $95.1 \%$, respectively) with a 2,4-/2,6-DCP ratio of $c a .135$ in each case. Even higher 2,4-/2,6DCP ratios of over 300 were achieved when poly(alkylene sulfide)s 5 ( $\mathrm{n}=3$,

$\mathrm{m}=9), 7(\mathrm{n}=\mathrm{m}=4)$, or $22(\mathrm{~m}=4)$ were used under the standard conditions, but in these cases the second chlorination step was slow and there were substantial quantities of 4-CP remaining, so that the actual yields of 2,4-DCP were not particularly high. The highest ratio (349.5) was with polymer 5 , so in this case a period at higher temperature $\left(55^{\circ} \mathrm{C}\right)$ and/or addition of extra sulfuryl chloride were used to try to increase the yield of 
2,4-DCP. Indeed, the yield of 2,4-DCP increased from 69.9 to $89.2 \%$ when the standard mixture was stirred at $55^{\circ} \mathrm{C}$ for $1 \mathrm{~h}$ before work-up. The 2,4-DCP yield increased further (to 93.3-96.6\%), with little change in the 2,4-/2,6-ratio, when more sulfuryl chloride was used and the reaction mixture was stirred at $55^{\circ} \mathrm{C}$ for $1 \mathrm{~h}$ before work-up. The highest yield of 2,4-DCP was 97.1\%, achieved when the amount of $\mathrm{SO}_{2} \mathrm{Cl}_{2}$ was 215 mmol for $100 \mathrm{mmol}$ of $\mathrm{P}$ and the reaction was heated at $55^{\circ} \mathrm{C}$ for $1 \mathrm{~h}$ before work-up, but it is not clear why in this case the selectivity was lower (possibly poorer temperature control). Increasing the reaction time in the double chlorination of $\mathrm{P}$ at $\mathrm{RT}$ showed little significant effect on the yield of 2,4-DCP.

Clearly, polymer 5 was the most efficient catalyst in both monochlorination and double chlorination of phenol in terms of para-selectivity and yields of 4-CP and 2,4-DCP, respectively. The best $4-\mathrm{CP} / 2-\mathrm{CP}$ ratio obtained from monochlorination of phenol was ca. 20 (Table 3), while, the 2,4-DCP/2,6-DCP ratio obtained from double chlorination of phe-nol was $c a$. 320, when polymer 5 was used. Therefore, this catalyst provides a $c a$. 16-fold increase in para-selectivity during the second chlorination step.

\section{Conclusion}

Highly para-regioselective chlorination systems for the chlorination of phenol and 2chlorophenol have been developed. The systems consist of a poly(alkylene sulfide), aluminum chloride and sulfuryl chloride. Such systems provide high yields of the parachlorinated phenols compared with those obtained in the absence of a poly(alkylene sulfide). The length of the spacer units (number of methylene groups) within the poly(alkylene sulfide) was found to be important for the regioselectivity of the chlorination reactions. High yields of the corresponding para-chlorinated phenols were obtained when at least one of the spacer units in the poly(alkylene sulfide) was short (2-4 methylene groups long). By use of one such poly(alkylene sulfide) it was possible to achieve direct double chlorination of phenol to give over $96 \%$ of 2,4-dichlorophenol with a 2,4-/2,6-DCP ratio of over 300 . The polymers are odorless, used at a low concentration, and can be recycled and reused at a commercial scale; therefore, such catalysts have potential for industrial use.

\section{Experimental section}

\subsection{General}

Chemicals and reagents were purchased from Aldrich Chemical Company. Sulfuryl chlo-ride was freshly distilled under nitrogen. The GC analyses were performed on a Shimadzu GC-2014 Gas Chromatograph using a capillary ZB Carbowax column (30 m, $0.32 \mathrm{~mm} \mathrm{ID)}$ and tetradecane was added as a standard. The column temperature was adjusted at $40^{\circ} \mathrm{C}$ for $3 \mathrm{~min}$, ramped to $220^{\circ} \mathrm{C}\left(10^{\circ} \mathrm{C} / \mathrm{min}\right)$ and held for $10 \mathrm{~min}$. The injector and detector temperatures were 300 and $250^{\circ} \mathrm{C}$, respectively.

\subsection{Synthesis of poly(alkylene sulfide)s}

\subsubsection{Alkanedithiol method (Scheme 1)}

A solution of $n$-butyllithium in hexane $(24.00 \mathrm{ml}, 2.5 \mathrm{M}, 60.00 \mathrm{mmol})$ was added over $10 \mathrm{~min}$ to a stirred solution $\left(-78^{\circ} \mathrm{C}\right)$ of the appropriate alkanedithiol $(30.00 \mathrm{mmol})$ in 
dry THF $(40 \mathrm{ml})$ under nitrogen. The mixture was stirred for $30 \mathrm{~min}$ at $-78^{\circ} \mathrm{C}$ and then allowed to warm to room temperature. The appropriate dibromoalkane $(27.00 \mathrm{mmol})$ was added and the mixture was stirred at room temperature for $60 \mathrm{~min}$. 1-Bromobutane (0.82 $\mathrm{g}, 6.00 \mathrm{mmol})$ was added and the mixture was stirred for $18 \mathrm{~h}$ at room temperature. The white solid obtained was collected by filtration, washed successively with water $(3 \times 25 \mathrm{ml})$, and dried at $50^{\circ} \mathrm{C}$ under reduced pressure to give a white solid. The melting points of the solids were recorded (see Table 1) and their proton NMR spectra were recorded in order to confirm the general nature of the polymers.

\subsubsection{Sodium sulfide method (Schemes 2 and 3)}

A mixture of an appropriate dibromoalkane (or an equimolar mixture of two dibromoalkanes; $3.00 \mathrm{~mol}$ in total) and sodium sulfide nonahydrate $(1000 \mathrm{~g}, 4.17 \mathrm{~mol})$ were placed in a round bottom flask (3 l) equipped with a magnetic bar and a water condenser. The mix-ture was heated under reflux for $4 \mathrm{~h}$ with vigorous stirring, by which time a very viscous material resulted. The mixture was poured into a clean beaker and cold water $(350 \mathrm{ml})$ was added slowly with stirring, and the mixture was left to cool. The solid obtained was col-lected by filtration, washed thoroughly with water $(3 \times 200 \mathrm{ml})$, and dried at $50^{\circ} \mathrm{C}$ under reduced pressure to give a white solid. Again, melting points of the solids were recorded (see Table 2) and their proton NMR spectra were recorded.

\subsection{Chlorination of phenol}

To a stirred mixture of melted phenol $(9.41 \mathrm{~g}, 0.10 \mathrm{~mol}), \mathrm{AlCl}_{3}(100 \mathrm{mg})$ and the appropri-ate poly(alkylene sulfide) $(100 \mathrm{mg}), \mathrm{SO}_{2} \mathrm{Cl}_{2}(8.90 \mathrm{ml}, 0.11 \mathrm{mmol})$ was slowly added over $2 \mathrm{~h}$ at room temperature (RT). The mixture was stirred at RT for $2 \mathrm{~h}$ and then quenched with water $(20 \mathrm{ml})$. The products were extracted using Et2O $(3 \times 30 \mathrm{ml})$ and the combined solu-tion was dried over $\mathrm{MgSO}_{4}$. The drying reagent was removed by filtration and the solvent was removed under reduced pressure until the weight was constant. A weighed aliquot of the products and a known quantity of tetradecane were used for the GC analysis. In some cases (see results and discussion) the mixture was warmed to $55^{\circ} \mathrm{C}$ for $1 \mathrm{~h}$ prior to work up or extra $\mathrm{SO}_{2} \mathrm{Cl} 2$ was used in the reaction.

\subsection{Chlorination of 2-chlorophenol}

The procedure was identical to that used for phenol, but 2-chlorophenol (12.86 g, 0.10 mol) was used instead of phenol.

\subsection{Double chlorination of phenol}

The procedure was identical with that used for phenol except that $\mathrm{SO}_{2} \mathrm{Cl}_{2}(17.00 \mathrm{ml}$, $0.21 \mathrm{mmol}$ ) was used instead of $8.90 \mathrm{ml}$.

\section{Acknowledgements}

A. S. Hegazy thanks Swansea and Cardiff Universities for financial support. G. A. El-Hiti is grateful to the Deanship of Scientific Research, King Saud University for funding through Vice Deanship of Scientific Research Chairs. 


\section{Disclosure statement}

No potential conflict of interest was reported by the authors.

\section{Funding}

This work was supported by Cardiff University; King Saud University [Grant Number Research Chairs]; Swansea University.

\section{ORCID}

Keith Smith (D) http://orcid.org/0000-0003-4838-5651

Gamal A. El-Hiti ${ }^{D}$ http://orcid.org/0000-0001-6675-3126

\section{References}

[1] Ullmann's encyclopedia of industrial chemistry. 6th ed. Weinheim: Wiley-VCH; 1998.

[2] Song Y. Insight into the mode of action of 2,4-dichlorophenoxyacetic acid (2,4-D) as an herbicide. J Integr Plant Biol. 2014;56:106-113.

[3] Peterson GE. The discovery and development of 2,4-D. Agricul His. 1967;41(3):243-254.

[4] Luther FB, Louis EB. Production of aromatic-oxyaliphatic carboxylates. United States Patent US 2,516,611. 1950.

[5] Nahide PD, Ramadoss V, Juárez-Ornelas KA, et al. In situ formed I(III)-based reagent for the electrophilic ortho-chlorination of phenols and phenol ethers: the use of PIFA- $\mathrm{AlCl}_{3}$ System. Eur J Org Chem. 2018;2018:485-493.

[6] Xiong X, Yeung Y-Y. Ammonium salt-catalyzed highly practical ortho-selective monohalogenation and phenylselenation of phenols: scope and applications. ACS Catal. 2018;8:4033-4043.

[7] Xin H, Yang S, An B, et al. Selective water-based oxychlorination of phenol with hydrogen peroxide catalysed by manganous sulfate. RSC Adv. 2017;7:13467-13472.

[8] Maddox SM, Dinh AN, Armenta F, et al. A practical Lewis base catalyzed electrophilic chlorination of arenes and heterocycles. Org Lett. 2016;18:5476-5479.

[9] Mu M, Snider BB. Syntheses of chloroisosulochrin and isosulochrin and biomimetic elaboration to maldoxin, maldoxone, dihydromaldoxin, and dechlorodihydromaldoxin. Org Lett. 2011;13:4224-4227.

[10] Denmark SE, Beutner GL. Lewis base catalysis in organic synthesis. Angew Chem Int Ed Engl. 2008;47:1560-1638.

[11] Smith K, El-Hiti GA. Catalytic, green and regioselective Friedel-Crafts acylation of simple aromatics and heterocycles over zeolites. Curr Org Chem. 2015;19:585-598.

[12] Smith K A, El-Hiti GA MH. Highly regioselective dinitration of toluene over zeolite H $\beta$. J Catal. 2013;297:244-247.

[13] Smith K, Al-Khalaf AKH, El-Hiti GA, et al. Highly regioselective di-tert-amylation of naph-thalene over reusable HM zeolite catalyst. Green Chem. 2012;14:1103-1110.

[14] Smith K, El-Hiti GA. Use of zeolites for green and para-selective electrophilic aromatic substitution reactions. Green Chem. 2011;13:1579-1608.

[15] Smith K, Ewart GM, El-Hiti GA, et al. Study of regioselective methanesulfonylation of simple aromatics with methanesulfonic anhydride in the presence of zeolite catalysts. Org Biomol Chem. 2004;2:3150-3154.

[16] Smith K, El-Hiti GA, Butters M. Acetylation of aromatic ethers using acetic anhydride over solid acid catalysts in a solvent-free system. Scope of the reaction for substituted ethers. Org Biomol Chem. 2003;1:1560-1564.

[17] Smith K, Roberts SD, El-Hiti GA. Study of regioselective dialkylation of naphthalene in the presence of reusable zeolite catalysts. Org Biomol Chem. 2003;1:1552-1559. 
[18] Smith K, El-Hiti GA, Bahzad D, et al. Highly ef $\mathrm{f}$ icient and selective electrophilic and free radical catalytic bromination reactions of simple aromatic compounds using bromine in the presence of reusable zeolites. J Chem Soc, Perkin Trans. 2000;1:2745-2752.

[19] Smith K, Butters M, Paget WE, et al. Highly selective monochlorination of aromatic compounds under mild conditions by tert-butyl hypochlorite in the presence of zeolites. Green Chem. 1999;1:83-90.

[20] Smith K, Zhenhua Z, Hodgson PKG. Synthesis of aromatic ketones by acylation of aryl ethers with carboxylic anhydrides in the presence of zeolite H- $\beta$ (H-BEA) in the absence of solvent. J Mol Catal A. 1998;134:121-128.

[21] Smith K, Musson A, DeBoos GA. A novel method for the nitration of simple aromatic compounds. J Org Chem. 1998;63:8448-8454.

[22] Smith K, Ewart GM, Randles KR. Regioselective methanesulfonylation of toluene catalysed by cation-exchanged zeolite beta. J Chem Soc, Perkin Trans. 1997;1:1085-1086.

[23] DeLaude L, Laszlo P, Smith K. Heightened selectivity in aromatic substitutions by the use of solid supports and catalysts. Acc Chem Res. 1993;26:607-613.

[24] Smith K, James DM, Matthews I, et al. Selective para-bromination of phenols via a regenerable polymer-bound tetralkylammonium tribromide. J Chem Soc Perkin Trans. 1992;1:1877-1878.

[25] Smith K, Butters M, Nay B. Highly para-selective mono-chlorination of aromatic compounds under mild conditions by $t$-butyl hypochlorite in the presence of zeolites. Synthesis (Stuttgart). 1985(12): 1157-1158.

[26] Gnaim JM, Sheldon RA. Shape-selective para-chlorination of phenol using sulfuryl chloride with the aid of microporous catalysts. Tetrahedron Lett. 2004;45:9397-9399.

[27] Ratton S, Leblanc J-C. Process for the selective chlorination of phenolic compounds. European Patent, EP0,196,260, 1986.

[28] Ogata Y, Kimura M, Kondo Y, et al. Orientation in the chlorination of phenol and of anisole with sodium and $t$-butyl hypochlorites in various solvents. J Chem Soc. Perkin Trans. 1984;2:451-453.

[29] Watson WD. Regioselective para-chlorination of activated aromatic compounds. J Org Chem. 1985;50:2145-2148.

[30] Watson WD. Chlorination with sulfuryl chloride. United States Patent US 3,920,757A, 1975.

[31] Smith K, Tzimas M, Brown CM, et al. Dialkyl sulf ides as selective catalysts for the chlorination of phenols. Sulfur Lett. 1999;22:89-101.

[32] Tzimas M, Smith K, Brown C, et al. Chlorination of aromatic compounds and catalysts therefor. European Patent EP0866049A2, 1998.

[33] Smith K, Al-Zuhairi AJ, El-Hiti GA, et al. Comparison of cyclic and polymeric disulfides as catalysts for the regioselective chlorination of phenols. J Sulfur Chem. 2015;36:74-85.

[34] Smith K, Williams D, El-Hiti GA. Regioselective chlorination of phenols in the presence of tetrahydrothiopyran derivatives. J Sulfur Chem. 2019;40:529-538.

[35] Smith K, Tzimas M, Brown CM, et al. Dithiaalkanes and modif ied Merrif ield resins as selective catalysts for the chlorination of phenols. Sulfur Lett. 1999;22:103-123.

[36] Tzimas M, Smith K, Brown C, et al. Chlorination of aromatic compounds and catalysts therefor. European Patent EP0866048A2, 1998.

[37] Smith K, Al-Zuhairi AJ, Elliott MC, et al. Regioselective synthesis of important chlorophenols in the presence of methylthioalkanes with remote SMe, OMe or $\mathrm{OH}$ substituents. J Sulfur Chem. 2018;39:607-621.

[38] Smith K, El-Hiti GA, Al-Zuhairi AJ. The synthesis of polymeric sulf ides by reaction of dihaloalkanes with sodium sulfide. J Sulfur Chem. 2011;32:521-531.

[39] Smith K, Balakit AA, El-Hiti GA. Poly(propylene sulfide)-borane: reagent for organic synthe-sis. Tetrahedron. 2012;68:7834-7839.

[40] Smith K, Balakit AA, Pardasani RT, et al. New polymeric sulfide-borane complexes: convenient hydroborating and reducing reagents. J Sulfur Chem. 2011;32:282-295. 